\title{
MATERIALS IN RESTORATIVE DENTISTRY
}

\author{
Floyd A. Peyton \\ University of Michigan, School of Dentistry \\ Ann Arbor, Mich.
}

Two major areas of practice are recognized in dentistry. One is directed toward the prevention of oral disease by the reduction of dental caries and the control of periodontal disturbances and oral lesions of all types in the mouth, the patient thereby being assured of the best possible oral health services from such preventive practice. The other area is the practice of restorative dentistry, which includes the treatment of localized infections and the preparation of restorations to replace lost tissue. It is with regard to this second area that an understanding of materials is important.

The construction of dental restorations and the practice of restorative dentistry are a necessity while people continue to suffer from involvements of the oral tissues. When teeth and adjacent tissues are lost by accident or disease, the lost tissues must be replaced by functionally and esthetically effective artificial substitutes. A major portion-variously estimated at 50-70\%-of dental service and time is devoted to these biomechanical procedures. Unfortunately, this condition is likely to continue throughout the present generation, or until research provides methods to assure a reduction of prevailing dental disorders. One should recognize, therefore, that restorative dental practice is important to the patient, is an accepted fact of the profession, depends on a knowledge and choice of available materials, and will continue to be needed in the future as a part of our dental health service.

In restorative procedures, two major activities must be recognized as fundamental: The proper treatment, preservation and care of the remaining oral tissues, with an evaluation of tissue tolerance, compatibility or tissue reaction to the various restorations; and the understanding of the fundamental nature, the physical and mechanical properties, and the functional and esthetic performance of the materials employed in the restoration. Dental materials science is concerned with all facets of these activities, and restorative dental practice involves the attempt to replace with appropriate substitutes either hard or soft tissues of the mouth which has been lost through accident or disease.

\section{Research Benefits}

During recent years, research on restorative materials has had a profound effect on all restorative dental practice. It is evident that research efforts will continue to result in further refinements, improvements and modifications in materials, techniques and procedures. ${ }^{1-3}$ Such advancement makes restorative practice more satisfying and more productive, both to the patient and to the dentist. In materials research, multidiscipline efforts are employed to solve existing problems in restorative dentistry. ${ }^{4}$ Studies are under way to correlate the efforts of the physical, chemical, or engineering scientist with the basic biologist or clinical investigator in order to achieve the greatest benefits for the practitioner and for the health of the patient. The results of this trend in research practice are encouraging, and the potential benefits are great.

One actual benefit is the development of improved and refined materials and techniques for restorative practice, ${ }^{5,6}$ in the form of better physical properties, simplification of technical procedures, development and introduction of new 
materials and discovery of their specific applications in practice. A wide range of materials is necessary for current restorative practice, including metals and alloys, plastics, ceramics and various combinations of substance. For each type of material, it is necessary to evaluate the tissue reaction it will evoke, its physical and mechanical characteristics and the influence of variation in manipulation, in order to estimate its serviceability in practice.

\section{Mouth Tissue Properties and Reactions}

Increased understanding of the nature and characteristics of hard and soft mouth tissues and their reaction to restorations has resulted from studies during recent years. The physical and mechanical properties of tooth tissue have been described in several studies, as well as the reaction of mouth tissues to various restorative materials. Information of this type is fundamental for the preservation of the remaining oral tissue and the success of the restoration or prosthesis.

Studies have demonstrated that a significant difference in hardness and strength exists between human dentin and enamel. For example, the average Knoop hardness value of enamel has been observed at $343 \pm 23$, while that of dentin is only $68 \pm 3 .^{7}$ In compression, the proportional limit of dentin is approximately 24,000 psi while that of enamel is $51,200 \mathrm{psi}$, with an ultimate compressive strength of 43,000 psi for dentin and 55,700 psi for human enamel. ${ }^{8,9}$ The elastic modulus of dentin is $2.65 \times 10^{8} \mathrm{psi}$ and of enamel $12.2 \times 10^{6}$ psi. Information of this type is vital in the design of tooth-supported restorations such as inlays, crowns and bridges. For example, in the construction of bridges it is good to know that the unfilled plastic materials are softer, weaker and more flexible than human dentin tooth tissue. Some of the cements have properties similar to dentin, and gold alloys in general are stronger, harder and more rigid than dentin, but all are softer than enamel tissue. ${ }^{9}$ Fused porcelain approaches the hardness value of enamel more nearly than most other restorative materials. Other properties show similar relations.

The thermal conductivity of tooth tissue has been studied and reported, along with comparisons with cements and amalgam fillings. ${ }^{10-12}$ Information of this type is helpful in providing proper thermal protection for the dental pulp and nerve tissue when large metallic restorations are necessary.

The average thermal conductivity of dentin is reported to be $1.36 \times 10^{-3}$ $\mathrm{cal} / \mathrm{sec} / \mathrm{cm}^{2} /{ }^{\circ} \mathrm{C} / \mathrm{cm}$, which is a little less than the value of $2.23 \times 10^{-3}$ for enamel, $2.5 \times 10^{-3}$ and $1.8 \times 10^{-3}$ for zinc phosphate and silicate cements respectively. These nonmetallic materials can serve as thermal insulators under silver amalgam having a thermal conductivity of $5.4 \times 10^{-2}$, or $90 \%$ gold- $10 \%$ copper alloy with a conductivity of approximately $0.29 \mathrm{cal} / \mathrm{sec} / \mathrm{cm}^{2} /{ }^{\circ} \mathrm{C} / \mathrm{cm}$. More information is needed on the proper insulation protection required under massive metal restorations, but it is known that a nonmetallic base gives some degree of protection under such restorations.

Studies are being reported for the first time which indicate the magnitude and direction of stress concentration, as well as the amount of deformation in fixed bridges of conventional design when loaded by forces similar to those encountered during mastication. ${ }^{13}$ Removable partial denture restorations are being subjected to similar stress analysis. Studies are being initiated to determine the stress concentration developed in the supporting tooth and bone tissues, since interest frequently lies in the preservation of the remaining body tissue, as well as in the design of the prosthesis that will keep stress concentration to a minimum. The methods of stress analysis being employed for these studies include a combi- 
nation of the engineering practices of using brittle lacquer coatings, electric strain gages, and photoelastic analysis of models. Such studies may have the beneficial effect of creating improved designs for, and better service from, partial denture restorations.

The reaction of the soft pulp or nerve tissue of the tooth to the acidity of cements, the monomer of plastic fillings, the leakage around or through restorations, and the cutting operations on enamel and dentin are being studied extensively. ${ }^{14-19}$ Study is being directed toward adequate protection against such reactive agents, and toward the development of a restorative material that will form true adhesion to the tooth tissue. To date, no such material is available.

The relative toxicity or tissue reaction to the many materials employed in restorative dentistry is receiving increased attention. A committee composed of representatives of areas of dental practice, biologic sciences, and pharmaco'ogy as well as of materials research and manufacture, are working through the Dental Materials Group of the International Association for Dental Research, with the Council on Dental Research of the American Dental Association in an effort to establish standardized methods for evaluating the compatibility of various types of materials. Progress has been made in grouping dental materials into three broad types and classes: (1) Those which contact parts of the body rather than the oral cavity during manipulation and fabrication; (2) those which contact mucous membranes and other soft tissues in service; and (3) those which contact the hard tooth tissues and may affect the vitality of the tooth tissue. Appropriate standard tests are being developed to evaluate materials of these types.

Where surgical implants are needed following oral surgery, the problems of tolerance, compatibility, toxic effects and functional strength are comparable to those of orthopedic or other prostheses where bone or soft tissue replacement materials are employed. The cobalt base alloys, stainless steel and a variety of plastic materials are employed for oral rehabilitation in cases where tissue has been lost as a result of accident or disease. The prosthodontist must be familiar with the materials available for maxillofacial restorations, obturators and similar prostheses. The materials science is more advanced in conventional restorative materials than in this highly specialized area of surgical implants, which requires a great deal more research.

\section{Metals and Alloys in Dentistry}

The variety of metals and the number of alloys used for dental restorations continue to increase. Not many years ago, only a few yellow gold alloys were available for cast and wrought structures, whereas today, a large variety of yellow and white gold alloys covering a range of compositions and properties can be obtained. The casting alloys are grouped into four types, ranging from soft, ductile products that can be adapted and adjusted with simple hand instruments to hard, high-strength alloys, subject to controlled heat treatment to alter and modify the properties, and suitable for casting to high precision. ${ }^{20} \mathrm{~A}$ comparable range of properties is available in gold alloy wires, bars or other prefabricated forms. The proportional limit of the cast alloys may be as high as 75,000 psi with a tensile strength value in excess of 100,000 psi. ${ }^{21,22}$ Gold alloy wires can have a proportional limit in excess of 100,000 psi with tensile strength values over $150,000 \mathrm{psi}$. Numerous basic studies on the fundamental metallurgical nature of the gold alloy systems have been reported; much is known about their crystal structure, and about the effect of composition and the influence of heat treatment on their properties. ${ }^{23-26}$

During the past 25 years, the cobalt-chromium alloys have almost completely 
replaced the gold alloys for precision-cast, removable, partial denture restorations. The composition, characteristic properties and fundamental nature of these dental alloys are now quite well understood. ${ }^{27-30}$ The effects of fabrication variables and other factors related to casting operations have been studied and described. ${ }^{31-33}$ Basically, and insofar as they apply to the field of surgical implant, the cobalt-chromium alloys are similar to the cobalt-base alloys. Progress has been made in the development of suitable mold materials for casting these highmelting alloys, and a shell-casting process was recently introduced which permits the formation of a completed casting within a period of one hour and which has numerous advantages over the more conventional casting methods. Perhaps more than $90 \%$ of all removable partial denture prostheses are produced from cobalt base alloys. The principal difference between their properties and those of the gold alloys lies in the increased hardness and greater modulus of elasticity or rigidity of the cobalt alloys. This added rigidity can have the effect of giving better stress distribution on the remaining supporting teeth.

Gold alloy wire was formerly employed for orthodontic springs and arch wires. Now, however, most orthodontic appliances are fabricated from stainless steel alloys. The 18-8 type austenitic stainless steel was popular until recently, when the 17-7 hardenable stainless steel was introduced for various applications. ${ }^{34}$ Because of the greater modulus of elasticity or rigidity, of the stainless steel in comparison to gold alloys, its resistance to tarnish or discoloration, and welldeveloped methods of fabrication available, it seems certain that the use of stainless steel in orthodontic applications will continue to grow.

Within recent years, a new group of alloys for cast restorations has become availab'e to the dental profession. These alloys are unique because they are supporting bases to which porcelain can be attached by fusion. A variety of alloys are available for this purpose, but most are alloys of gold with 8-10\% platinum, $4-5 \%$ palladium and $0.2-0.5 \%$ of tin, iron, and indium. ${ }^{35,36}$ One alloy is basically a combination of palladium, silver and ruthenium, and another is developed from a cobalt-chromium base metal formulation. These alloys are appropriate for crown and bridge restorations; and in general, the properties of the special alloys are an improvement over conventional gold casting alloys intended for the same purpose. For this type restoration, it has been necessary to develop both a special alloy and mold material, as well as to modify the porcelain to be attached to the metal frame. This has been accomplished to an extent such that lasting attachment of the porcelain to the metal is now possible. Greater problems exist in the production of accurate castings from the high-melting alloys, and in the development of the positive esthetic potential of porcelain veneers, a characteristic problem with fused porcelain restorations.

\section{Silver Amalgam Restorations}

After more than 75 years of use, silver amalgam continues to be one of the most satisfactory restorative dental materials. Studies have described the basic nature of the silver-tin alloy which is combined with mercury to form amalgam. ${ }^{38,39}$ Other studies have described the reaction between mercury and the silver alloy, ${ }^{40,41}$ Available evidence indicates that most variables of manipulation have some influence on the properties of the amalgam mass. ${ }^{4-46}$ In spite of the poisonous nature of some mercury compounds, there is no clinical or experimental evidence to suggest that silver amalgam has any seriously toxic effect on most patients. The use of silver amalgam is unique to dentistry, since no other branch of health science employs this type of material. 


\section{Plastics in Dentistry}

Restorative procedure in dentistry has always been dependent on contemporary developments in related sciences and arts. In recent years, the introduction of synthetic plastics has greatly advanced the production of good fittings, and of functionally and esthetically satisfactory restorations and prostheses. Resins can be extensively used in restorative dentistry as a result of the many hours devoted to their development, evaluation, and adaptation for specific problems. Most commercially available plastic products have been evaluated, some adapted, and many discarded as being impractical for dental applications.

Plastics are used successfully in the formation of complete and partial prostheses, plastic teeth, repair and reline materials, attractive veneers, and soft liners for temporary relief of sore tissues. ${ }^{47}$ Direct tooth-filling applications, veneers, and crown forms have some specific indications, and maxillofacial prostheses involving both intra- and extraoral replacement of hard or soft tissues require special qualities in the resin. Protective mouth guards, plastic cements, impression trays, or inlay and other pattern forms represent some of the dental uses of resin plastic. Both silicone and polysulfide synthetic rubber materials serve satisfactorily as elastic impression materials in dentistry. The range of desirable physical and mechanical properties is as varied as the uses, extending from soft, flexible materials that polymerize while the patient waits, to harder, more rigid materials that can be used for bridges or other prostheses. No one material is equally satisfactory for all dental applications.

\section{Complete and Partial Denture Prostheses}

For the construction of dental prostheses, there exists a variety of acrylic copolymers, blended acrylic-vinyl plastics, and polystyrene plus a variety of processing techniques. Recent studies have demonstrated that these materials can be used to produce acceptable dentures if the appropriate construction procedure is followed faithfully. ${ }^{48,49}$ The superiority of one technique or material over another has not been established, though an individual quality of one material or method of processing may be a limited improvement over another. Serviceable, attractive prosthetic restorations with excellent dimensional relationships are readily constructed if proper technical procedures are followed. There is evidence that nylon is definitely contraindicated as a denture material because of difficulty in processing and serviceability. ${ }^{50}$

Recent research studies have shown that the wettability of poly- (methyl methacrylate) can be increased by coating with silicon tetrachloride. ${ }^{51}$ The wettability of treated plastic was increased by $50-70 \%$ with saliva and water. Improved cleanliness and nonadherence to chewing gum to denture teeth was observed by patients whose dentures had been coated.

Artificial plastic teeth are both esthetically and functionally serviceable. In many instances, they are to be preferred to porcelain teeth, but not in all applications. The choice depends on the clinical diagnosis. A recent report indicates that plastic is used in the manufacture of approximately $30 \%$ of all artificial teeth in the United States, while it is more widely used in other countries. ${ }^{47}$

It frequently happens that a soft resilient liner attached to the hard acrylic base gives added comfort to the patient. ${ }^{52}$ Such liners may be used for a short time to prevent chronic soreness from dentures, or as adjuncts in tissue conditioning. Longer use may be indicated following irradiation therapy, or in the reparation of congenital or acquired oral defects. In all instances, the fundamental principles of denture construction are to be observed, and soft liners are 
exists between the tooth and the restoration. ${ }^{64,85}$ As a result, marginal penetraneither considered permanent in nature nor recommended for all patients by most prosthedontists.

Important qualities of these resilient materials include color stability, bond strength, tear strength, permanent resiliency, and ease of finishing or polishing. The products available differ appreciably in many of their properties, and give significantly different clinical performances. Most of the products are modified or plasticized acrylic resins, but one is a vinyl resin and two are silicones. ${ }^{53} \mathrm{Com}$ parative tests have shown one silicone material to be relatively soft, with a durometer hardness value of 24 which is retained after one month in water at mouth temperature. One popular acrylic material shows a hardness of 25 which increases to 40 after one month, and another possesses an initial hardness of 52, which increases to 55 after standing. Other qualities vary accordingly. An unusual and unfavorable quality of the silicone liner is its ability to support yeast growth (Candida albicans, fungus colonies) in some mouths. ${ }^{54}$ The means of overcoming this characteristic have not been discovered.

\section{Plastic Anterior Fillings and Veneers on Fixed Prosthesis}

Some improvements have been made in recent years in restorative resins that polymerize at mouth temperature. New products have more color stability and may develop better marginal adaptation than older products. These materials are still best suited for protected restorations of the cervical or proximal type which are free from stress concentration during mastication, since all plastics are readily deformed elastically if used in locations where large stresses are applied. The plastic fillings are subject to leakage due to polymerization shrinkage or a coefficient of expansion different from that of the tooth tissue. They do not inhibit caries activity as do silicate cements, and to date, there has been no success in developing a plastic cement or filling material with anticariogenic properties. Some investigators urge caution on the basis of possible pulp reaction to plastic fillings, and discourage their use in deep cavities. ${ }^{55}$

A new type of plastic filling material has been introduced in recent months which contains approximately $70 \%$ inorganic vitreous filler, with the remaining $30 \%$ an organic binder made up of blended acrylates and cross linking agents. ${ }^{56}$ Like the others, this material does not adhere to tooth tissue. Because of the filler, it has reduced polymerization shrinkage and lower thermal expansion than unfilled plastics. While it shows some promise, further improvements in the material are desirable.

The desire for attractive veneers on crown and bridge restorations has produced renewed interest in plastic facings and veneers. ${ }^{57-59}$ They are less expensive to fabricate and easier to replace than restorations of porcelain fused to gold. Epoxy plastics and glass fiber-filled resins have been recommended in this context, but they offer no advantage over the heat-polymerized acrylics and vinylacrylic blended materials. While veneer restorations can be formed from any of the suggested plastics, presently the most color-stable and dimensionally satisfactory are the acrylic and vinyl-acrylic materials.

\section{Anterior Filling Materials}

Researchers and practitioners are increasingly concerned by the fact that no filling material or cement adheres to the tooth tissue. ${ }^{60,61}$ This condition has been recognized generally for at least 25 years; and during the past five years, extensive studies have established that no existing material adheres to tooth tissue. ${ }^{62,63}$ Because of this lack of true adhesion, a space or a crevice of varying dimensions 
exists between the tooth and the restoration. ${ }^{64,85}$ As a result, marginal penetration may occur, which in turn may contribute to recurrent caries, pulpal response and fracture of the restoration.

Several methods of study have been employed to determine the extent of leakage that may occur, ${ }^{86.69}$ including studies of radioisotope penetration, leakage from applied air pressure, penetration of dyes around and under the fillings, bacterial penetration, and percolation of liquids. The degree and magnitude of the leakage differs to some extent with the choice of material and technique of use. In view of the fact that leakage under restorations has been a perpetual condition, it is a credit to the integrity and skill of clinicians in the past that their restorations of gold foil, amalgam, well-designed cast crowns, or inlays have given service for $20-30$ or more years, indicating that well-placed restorations can be serviceable and satisfying.

Studies related to the development of a truly adhesive material for tooth tissue are underway and some progress is being made, although to this time, no completely acceptable material is available. Such studies involve not only the problems of surface chemical reactions, wetting and spreading of liquids, the mechanism of adhesion, solubilities and related physicochemical problems, but also the development of compatible cavity liners or filling materials and cements with improved properties and surface qualities. If such studies continue and are encouraged, they may produce results of great potential significance. In the meantime, it is appropriate that effort be spent on becoming familiar with the nature and quality of acceptable materials currently available. Many investigators and practitioners believe that fine restorative results may be achieved with existing materials.

\section{Cement Base and Cavity Liners}

In recent years, interest has centered on the protection of the pulp by means of the proper cement base and/or cavity liner in deep and extensive cavities. ${ }^{70,71}$ Where indicated, zinc oxide-eugenol or calcium hydroxide pastes provide suitable protection, sedation, or thermal insulation. They may reduce the acid penetration to the pulp area and possibly by neutralizing the free acid. The presence of a suitable varnish with the base gives added protection.

\section{Product Quality Control}

In the development and refinement of restorative materials, investigators are being guided-and the profession protected-by an increasing number of American Dental Association Specifications. ${ }^{30}$ These serve as a basis for quality control of products, and there is practical evidence to indicate that products which comply with ADA specifications will produce serviceable and acceptable restorations. Eighteen such standards are available and an additional ten are being prepared. The specifications available for gold alloys, cobalt-chrome alloys, amalgam, mercury, plastics, cements and other materials have done much to maintain the high quality of products available to the American dental practitioner. Evidence indicates that techniques of processing more than choice of materials influence the quality of many products.

Though it is impossible to predict what further trends will develop or what additional refinements will take place in restorative materials, it is certain that many of the challenges of restorative practice will be met in the years ahead by further modifications and improvements of materials. The practitioner may anticipate advances through research during the next ten years which will equal or surpass those of the past, and which hopefully will continue giving rise to more efficient and more effective clinical practices. 


\section{REFERENCES}

1. Paffendarger, G. C. 1959. Physical research. J. Am. Dental Assoc. 58: 97.

2. Docking, A. R. 1961. Why carry out research and testing of restorative dental materials. Australian Dental J. 6: 326.

3. Phillips, R. W. 1964. Some current observations on restorative materials. Australian Dental J. 9: 258 .

4. Arnold, F. A. 1964. Trends in dental research. J. Am. Dental Assoc. 68: 807.

5 RYGE, G. 1963. Materials used in restorative dentistry. In Dental Clinics of North America : 865. W. B. Saunders Co., Philadelphia, Pa.

6. Peyton, F. A. 1963. Restorative materials: Some trends and developments. J. Michigan State Dental Assoc. 45: 313.

7. Craig, R. G. \& F. A. Peyton. 1958. The microhardness of enamel and dentin. J. Dental Res. 37: 661 .

8. Craig, R. G. \& F. A. Peyton. 1958. Elastic and mechanical properties of human dentin. J. Dental Res. 37: 710.

9. Craig, R. G., F. A. Peyton \& D. W. Johnson. 1961. Compressive properties of enamel, dental cements, and gold. J. Dental Res. 40: 939.

10. Craig, R. G. \& F. A. Peyton. 1961. Thermal conductivity of tooth structure, dental cements, and amalgam. J. Dental Res. 40: 411.

11. Phillips, R. W., R. J. Johnson \& L. J. Phillips. 1956. An improved method for measuring the coefficient of thermal conductivity of dental cement. J. Am. Dental Assoc. 53: 577.

12. Soyenkoff, B. C. \& J. H. OKun. 1958. Thermal conductivity measurements of dental tissues with the aid of thermisters. J. Am. Dental Assoc. 57: 23.

13. Craig, R. G. \& F. A. Peyton. 1965. Measurement of stresses in fixed-bridge restorations using a brittle coating technique. J. Dental Res. 44: 756.

14. Weiss, M. B., M. Massler \& J. M. Spence. 1963. Operative effects on adult dental pulp. Dental Progress, 4: 10.

15. Stanley, H. \& H. Swerdlow. 1960. Biological effects of various cutting methods in cavity preparation: The part pressure plays in pulpal response. J. Am. Dental Assoc. 61: 450 .

16. BuONocore, M. G. 1963. Principles of adhesive retention and adhesive restorative materials. J. Am. Dental Assoc. 67: 382.

17. Langeland, K. \& L. K. Langeland. 1965. Pulp reactions to crown preparations, impressions, temporary crown fixation, and permanent cementation. J. Prosthetic Dentistry 15: 129.

18. Mrtchell, J. F., M. G. Buonocore \& S. Shazer. 1962. Pulp reactions to silicate cement and other materials: Relation to cavity depth. J. Dental Res. 41: 591.

19. Swerdlow, H. \& H. R. Stanley. 1962. Response of the human dental pulp to amalgam restorations. Oral Surg. Oral Med. Oral Pathol. 15: 499.

20. A.D.A. Council on Dental. Research. 1966. Guide to Dental Materials, 3rd ed. Am. Dental Assoc. Chicago, Ill.

21. Bush, S. H., D. F. TAylor \& F. A. Peyton. 1951. A comparison of the mechanical properties, chemical compositions, and microstructures of dental gold wires. J. Prosthetic Dentistry 1: 177 .

22. BUSH, S. H. 1952. A statistical analysis of the mechanical properties of cast and wrought gold dental alloys, A.S.T.M. Bull. 185; 46-50.

23. Houghton, J. L. \& R. J. M. Payne. 1931. Transformations in the gold-copper alloys. J. Inst. Metals 46: 457.

24. MeriCA, P. D. 1932. The age-hardening of metals. Trans. A.I.M.E. (Met. Div.) 99: 13.

25. Wise, E. M. \& J. T. EASH. 1933. The role of platinum metals in dental alloys. 3rd in a series. Trans. A.I.M.E. (Met. Div.) 104: 276.

26. WISE, E. M. 1948. Cast gold dental alloys. Am. Soc. Metals Handbook, Cleveland 1120.

27. Asgar, K. \& F. A. Peyton. 1961. Effect of microstructure on the physical properties of cobalt-base alloys. J. Dental Res. 40: 63 .

28. Asgar, K. \& F. A. PEyton. 1961. Effect of casting conditions on some mechanical properties of cobalt-base alloys. J. Dental Res. 40:73.

29. AsGar, K. \& F. A. Peyton. 1962. Flow and fracture of dental alloys determined by a microbend tester. J. Dental Res. 41 : 142.

30. Earnshaw, R. 1956. Cobalt-chromium alloys in dentistry. Brit. Dental J. 101: 67.

31. EARNSHAw, R. 1960. Investments for casting cobalt-chromium alloys. Brit. Dental J. 108: 389 . 
32. Peyton, F. A. 1958. Cast chromium-cobalt alloys. Symposium on Dental Materials. In Dental Clinics of North America, 759. W. B. Saunders \& Co., Philadelphia, Pa.

33. Dootz, E. R., R. G. Craig \& F. A. Peyton. 1965. Influence of investments and duplicating procedures on the accuracy of partial denture castings. J. Prosthetic Dentistry 15: 679 .

34. Craig, R. G., H. J. Slesnick \& F. A. Peyton. 1965. Application of $17-7$ precipitationhardenable stainless steel in dentistry. J. Dental Res. 44: 587.

35. Ryge, G. 1965. Current American research on porcelain-fused-to-metal restorations. Intern. Dent. J. 15: 385 ,

36. Shell, J. S. \& J. P. Nielsen. 1962. Study of the bond between gold alloys and porcelain. J. Dental Res. 41 : 1424.

37. Schnell, R. J., G. Mumford \& R. W. Phillips. 1963. An evaluation of phosphate bonded investments used with a high fusing gold alloy. J. Prosthetic Dentistry 13: 324.

38. Ryge, G., J. C. Moffett \& A. G. Barkow, 1953. Microstructural observations and X-ray diffraction studies of silver-tin amalgams. J. Dental Res. 32:152.

39. MURPHY, A. J. 1926. The constitution of the alloys of silver and tin. J. Inst. Metals 35: 107 .

40. Mitchell, J. A., I. C. Schoonover, G. Dickinson \& J. C. Vacher. 1955 . Some factors affecting the dimensional stability of Ag-Sn (Cm- $\mathrm{Zn})$ amalgams. J. Dental Res. 34: 273.

41. Ryge, G., R. F. TElford \& C. W. Fairhurst. 1957. Strength and phase formation of dental amalgam. J. Dental Res. 36: 986.

42. Schoonover, I. C., W. Souder \& J. R. Beall. 1942. Excessive expansion of dental amalgam. J. Am. Dental Assoc. 29: 1825.

43. WARE, A. L. \& A. R. Docking. 1955. The effect of manipulative variables on dental amalgams. Australian Dental J. 58: 283; 59: 167.

44. Peyton, F. A. \& E. L. Liatukas. 1961. Compressive strength of amalgam as influenced by different condensation forces. J. Prosthetic Dentistry $11: 934$.

45. Taylor, N. O., W. T. Sweeney, D. B. Mahler \& E. J. Dinger. 1949. The effects of variable factors on crushing strengths of dental amalgams. J. Dental Res, 28: 228.

46. Wilson, C. J. \& G. Ryge. 1963. Clinical study of dental amalgam. J. Am. Dental Assoc. 66: 763.

47. Brauer, G. M. 1966. Dental applications of polymers: A review. J. Am. Dental Assoc. $72: 1151$.

48. Peyton, F. A. \& D. H. Anthony. 1963. Evaluation of dentures processed by different techniques. J. Prosthetic Dentistry 13: 269.

49. Woelfel, J. B., G. C. Paffenbarger \& W. T. Sweeney. 1963. Some physical properties of organic denture base materials. J. Am. Dental Assoc. 67: 489.

50. GEORGE, W. A. 1965. Notes and comments. Dental Abstracts. 10:9.

51. O'BrIEN, W. J. \& G. RYGE. 1965. Wettability of poly- (methyl methacrylate) treated with silicone tetrachloride. J. Prosthetic Dentistry 15: 304.

52. Gonzalez, J. B. \& W. R. LANEY. 1966. Resilient materials for denture prostheses. J. Prosthetic Dentistry 16: 438.

53. Eick, J. D., R. G. Craig \& F. A. Peyton. 1962. Properties of resilient denture liners in simulated mouth conditions. J. Prosthetic Dentistry 12: 1043.

54. GibBons, P. 1965. Clinical and bacteriological findings in patients wearing silastic 390 soft liner. J. Michigan State Dental Assoc. 47: 64.

55. MAssler, M. 1965. Biologic considerations in the selection and use of restorative materials. In Dental Clinics of North America, 131. W. B. Saunders Co., Philadelphia, Pa.

56. Langeland, L. K., J. Guttuso, D. R. Jerome \& K. Langeland. 1966. Histologic and clinical comparison of addent with silicate cements and cold-curing materials. J. Am. Dental Assoc. 72: 373.

57. Peyton, F. A. \& R. G. Craig, 1963. Current evaluation of plastics in crown and bridge prostheses. J. Prosthetic Dentistry 13: 743.

58. Kafalias, M. C., M. L. Swartz \& R. W. Phillips. 1963. Physical properties of selected dental resins, Part I. J. Prosthetic Dentistry 13: 1083.

59. Fitzroy, D. C., M. L. Swartz \& R. W. Phחlips, 1963. Physical properties of selected dental resins, Part II. J. Prosthetic Dentistry 13: 1108.

60. VOLKeR, J. F. 1962. Report of the committee on scientific investigation of the American academy of restorative dentistry. J. Prosthetic Dentistry 12: 770 .

61. Phinlips, R. W. 1963. Report of the committe on scientific investigations of the American academy of restorative dentistry. J. Prosthetic Dentistry 13: 515 .

62. MYERS, C. L., G. RYGE \& J. F. GLENN. 1963. In vivo test for bonding strength. J. Dental Res. 42: 907. 
63. Phillips, R. W., H. W. Grllmore, M. L. Swartz \& S. I. Schenker. 1961. Adaptation of restorations in vivo as assessed by $\mathrm{Ca}^{45} \mathrm{~J}$. Am. Dental Assoc. 62: 9.

64. Nelson, R. J., R. B. Wolcott \& G. C. Paffenbarger. 1952. Fluid exchange at the margins of dental restorations. J. Am. Dental Assoc. 44: 288.

65. Parris, L. \& P. Kapsimalis. 1960 . The effect of temperature change on the sealing properties of temporary filling materials. Oral Surg. Oral Med. Oral Pathol. 13: 982.

66. Lyelle, J., D. BARBer \& M. MASSLER. 1964. Effects of saliva and sulfide solutions on the marginal seal of amalgam restorations. J. Dental Res. 43: 375 .

67. Fiasconano, J. E. \& H. Sherman. 1952. Sealing properties of acrylics. N.Y. State Dental J. 18: 198.

68. Pinto, J. \& M. G. Buonocore. 1963. Effect of bones and cavity liners on marginal leakage of filling materials. N.Y. State Dental J. 28: 199.

69. Mortensen, D. M., N. E. Boucher \& G. RYge. 1963. Method of testing for marginal leakage of dental restorations with bacteria. Abs. Gen. Meeting. Intern. Assoc. Dental Res. 33.

70. Swartz, M. L., R. W. Phillips \& N. Chamberlain. 1962. Continued studies on the permeability of cavity liners. J. Dental Res. $41: 66$.

71. PAPpas, A. \& M. Massler. 1959. Bio-assay of cavity liners under silicate cement fillings in rat incisors. J. Dentistry Children 26: 335. 